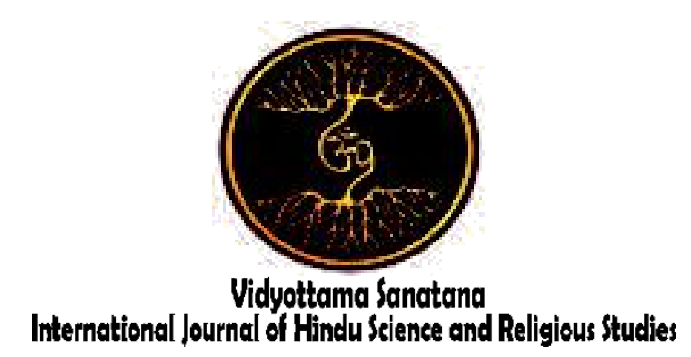

Vol. 2 No. 2 October 2018

\title{
Asana Yoga Meditation As A Spiritual Development Ananda Marga Ashram Denpasar (Perspectives Theology Hindu)
}

\author{
By: \\ I Nyoman Sukarsa \\ Institut Hindu Dharma Negeri Denpasar \\ E-mail: sukarsainyoman@gmail.com
}

Received: July 25, 2018

Accepted: September 30, 2018

Published: October 31, 2018

\begin{abstract}
Research conducted at Ashram Yoga Ananda Marga guided by a desire to know more about the benefits of yoga asanas for an individual to develop himself physically, mentally and spiritually, yogis who have developed this yoga since thousands of years ago, until now characterized separately by emphasizing according to the type that occupied, in its implementation for the benefit of the health and maximize efforts to accelerate achieved the ultimate goal in life. The objectives to be achieved is to understand more clearly focused and in-depth about asana techniques as meditation Spiritual development is developed and implemented by a group Ananda Marga Ashram spiritual in Denpasar. The study used several theories, namely the theory of structural functionalism, system theory of learning, theory of Hindu theology. In this study the methods used in qualitative approach of primary data obtained through field research and secondary data which can be obtained from some of the literature that has relevance to the problems examined. Furthermore, all the collected data are analyzed in the description. Based on the data analysis, it can be concluded about the practice of yoga asanas, in its approach, asana yoga training system applied is the patterns not only classical but more modernity according to the times. Ananda Marga implement training technique known as practical Rajadhiraja which is an extension of the ancient Rajayoga system, also known as Astanga yoga. It is practiced in a relatively slow speed and each pose is repeated in a systematic way. The goal in the repetition is to balance the secretion of hormones that are essential for peace of mind.
\end{abstract}

Keywords: Asana Yoga, Spiritual, Happiness 


\section{Introduction}

In Hinduism, the purpose of life is "yes Jagathita Moksartham caiti dharma," meaning that the goal of human life is for happiness in the world and the Hereafter happiness based on the teachings of dharma. The opportunity is born once as real human beings is to achieve this goal is to free themselves from the cycle of samsara.

By being aware of it, in Hinduism has a variety of alternative roads in an effort to achieve the ultimate goal aspired includes Karma Yoga, Bhakti Yoga, Jnana Yoga, and Raja Yoga, of course choose one to be practiced. In Patanjali Yoga talked about the concept of yoga called Yoga Astangga, namely yama, niyama, asana, pranayama, prathyahara, dharana, dhyana and samadhi.

Yoga is a system that allows an individual to develop himself physically, mentally and spiritually, one aspect of yoga is beneficial for developing spiritual health, with spiritual progress, the mind will develop capacity, and will expand the boundary line, until it merges in The highest entity. During progress can develop many capabilities that are sattwam (Sarkar, 1992: 174).

In its development until today there are many types of yoga, and have the same parent is the Yoga Sutra written by Patanjali. various types of yoga and meditation developed by spiritual study group at the present time is very interesting to study, because each of the development of these types of yoga has its own characteristics. Spiritual study group also develops each one of the Patanjali Yoga concept with more emphasis according to the type to be practiced.

Needs to be observed and reflected deeper if deep spiritual. In this regard will focus investigated one of the international spiritual community. One of its branches in Bali itself that Ananda Marga. The Ashram is taught more emphasis on the practice of Yoga Asana. Yoga Asana is very much usefulness in health, and that helps in preparing the body for spiritual meditation. Yoga Asana will have an impact on the physical, flexibility, flexibelitas body, as a driving force to develop meditation spititual, different from the others. In the observation that there are peculiarities that are mounted in the practice of yoga asana that is, in yoga asana specifics emphasis on refining gland in each chakra massaged and stretched during the asana is done repeatedly from four to eight times in a position that is on hold and in the period puraka particular with the setting of breath, kumbaka and recaka, without ignoring other aspects, so that every massage glands on the disc, will produce the hormone balance in the body and mind so as to produce a serenity yourself. After completing the asanas performed massage or massage, as it will enhance the efforts refreshment of asana [Ananda Marga Publications, 2005: 53].

The Ashram spiritual study group has been established since 1979, although growth is not spectacular, but still the road. Ashram in terms of appearance is not so good or flashy than others. Members in the Ashram is quite a lot and some of its members had independently become yoga teachers elsewhere. In each of his followers practice an average of only 15 people. The participants followed by a community of Hindu, Christian, Buddhist and Muslim. In other observations, in this Ashram applied Brahmacarii teachings are good and were given a room on the other to become Acharya.

Deepening exercises are indispensable in order to advance in the spiritual life, by implementing the teachings Brahmacari not married and abstain from sexual intercourse entirely impossible. The composition of the people of the world are already experiencing changes that are so large that a person may not abstain from sexual intercourse since she started studied and became a disciple. Explained that throughout the world there are many institutions of various types of knowledge, but yet there is a recognized institution for educating students in the principles of Brahmacari. Be confirmed that's very difficult to progress in the spiritual life if one does not practice abstinence marital 
relationship. According to Sri Caitanya Mahaprabu said that at the time of this time according to the rules of the scriptures only realize the Almighty processes that may be running is how to praise the holy names of the Lord. Therefore, it is clear, requires deepening, exercise earnest and high discipline because it is not easy to run a Brahmacari teachings as practiced by some communities in Ananda Marga Ashram.

\section{Methods}

In this research, conducted through the Hindu theology studies approach with qualitative methods. This research was conducted in Ananda Marga Ashram Denpasar. The type of data used in this study is qualitative data derived from primary data sources and secondary data. Data obtained from the results of observations and informants who have been determined using snowball sampling techniques in accordance with the issues discussed. Techniques used in this research is observation, interviews, documentation and literature. Data were analyzed with descriptive qualitative technique using structural functionalism theory, the theory of learning systems and theory of symbols and meanings that the results are presented using formal and informal methods.

\section{Results And Discussion}

Analysis of the implementation of yoga in order disclosure of changes that occur each individual in following the yoga asanas in an atmosphere of diversity to achieve harmony and tranquility. On the other hand, although not easy to measure learning outcomes which may not be the same every learner Trianto (in wahyuni, 2010: 30). The psychology of the lives of many available time to pamper and provide physical pleasure to find peace, but instead they obtained is physical tension, mental and emotional. Therefore implement asana will have more power with various problems (Saraswati,2002:2).

Here clearly needed is new thinking ability with concentration, of course, be done in a way that is properly structured, focused to achieve optimal results. Physical is one of the criteria to support the practice of meditation is perfect. The goal is to get the body that is flexible in order to balance the energy that is free from disease. To meet the needs of physically not as fast as desirable but necessary time through the learning process. The experience gained with a good environment greatly affects the physical and mindset in an effort to raise awareness that brings peace of self so as to obtain healthy physically, mentally, and spiritually. While on the other hand in the learning process of a relationship between the members of that is based on a sense of togetherness, it certainly can foster a relationship based situational remedy achieve objectives of common interest with a cozy and intimate atmosphere, so it will give a fresh new look while maintaining a harmonious relationship.

Analysis for the achievement of objectives, in the process of learning yoga asana is very necessary to understand how the body's systems work of the foods so as to avoid excessive eating. In this case there are two functions of the digestive system is the first to absorb nutrients for a healthy body and a second to remove toxins. If the system is not functioning removal of toxins will cause disease. Therefore expenditure regularly toxins in the body is vital to maintaining good health. the food is very influential on the bodies and minds. There are three kinds of food that need to be understood, as follows; (1) Food Satvika, foods that are good for the body and mind such as fruits, most vegetables, nuts and dairy products, tubers. Satvik meal will make the good behavior and speech is smooth and soft. Easy concentrations and have confidence. (2) Food rajasika, the food was not too negative impacts, such as coffee, tea, chocolate, and soft drinks. The food is good for the body but not necessarily good for the mind. Consuming these foods will not adversely affect the spiritual progress. (3) Food tamasika, the food is not good for the mind as body and, red meat, fish, chicken, egg, onion, mushrooms and garlic. Besides, 
these foods tends to stimulate such as laziness, ignorance, sleepiness, greed, no patience, no hygiene and can cause a variety of diseases, also inhibits increase spiritual (Nabaniilananda, 2012: 37).

The food is very influential and important for humans to life. Annam vai pranah which means the food is prana or life itself. Ahar suddhau satva suddhi which means the food is pure, the mind also becomes sacred. Therefore, in order to mean either for themselves or someone else, you should choose foods that Satvika man in her life. The universe is a wide range of food for humans, with the energy of good food so it can clean up and be amrta for the body (Atharvaveda: 03.18.56).

Man was created to have the privilege and the glory of its own compared to other creatures creations. Humans have wiweka so as to distinguish the good and not good. A healthy diet will affect the good behavior. therefore understanding requires time, a calm mind, clear to understand the purpose. Put the learning objectives for humans to evolve into a character so well that his life could be useful for others and for themselves. for that a healthy lifestyle is not overlooked, if you want the achievement of unification, the necessary food of good quality.

Asana dependent person's intellectual development to develop good attitudes to improve health. Asana should be developed and then look for the right techniques vary so attractive, beautiful to follow tirelessly, poses as encouragement and motivate yourself to keep it fresh and make healthy physical with good and noble purpose. With this pattern a person be a role model lead to changes in behavior. Learning asana technique not only to get the physical health, proper and correct asanas actually teach people to get physical flexibility, so as to obtain the beauty and happiness as well as the most noble objectives to be achieved. Through good teaching, let alone a perfect right to be easier to reach for the beauty of life towards happiness. Constructing reality itself, based on experience, so that individual knowledge possessed became a function of experience mental structures and the conviction of a previously (Smith, 2009: 88).

Benefits gained in its development. (a) .In essence in understanding the concepts of spiritual it is best to first by practicing meditation to develop intuition rather than just studying intellectual ideas. If you want to understand yourself through meditation should be supported by healthy physical media that the practice of yoga asanas. spiritual meditation is essentially concentrate on a spiritual idea associated with infinite consciousness. So the point is an attempt to unify our sense of ego into infinite consciousness (Anandamurti, 2004: 121). (b). Benefit from the moral, morality regarding formation attitudes and moral behavior is good or good manners in any implementing activities in the community, this is the basis of spiritual activity and is not the purpose of spiritual life, because at any moment can be deleted but nevertheless it is also very important morality means for continuity and regularity of life. Morality is only as good attribute to humans and is a preliminary step in the spiritual path through sadhana. It is very necessary mental equilibrium (Anandamurti, 1998: 2).

Morality is a human nature, man is obliged to adjust the properties of nature and perform all obligations perfectly. Humans only seen as a good of the human family and the creatures of God, if he is in his life carrying out a good morality, so morality can not be separated from one's lifestyle. In man there triguna effect, therefore it is necessary should be considered as food ingredients selected from the group creature lowest level of development of consciousness, vegetables, fruits clean and nutritious. (c). Ethics, the meaning of which is intended as a collection of knowledge concerning the assessment of human actions. The things that are ethical is a predicate used to distinguish things certain human actions. So ethics is one that is used to discuss or investigate the value in moral conduct or review a matter of morality or morality Dahlan (2003: 194). (d). Culture, the benefits obtained with different cultural backgrounds and different beliefs 
also vary, asana in its application developed towards more modern so as to give the impression of a sense of brotherhood there is no visible difference, a growing sense of togetherness and the participants feel comfortable. (e). Aesthetics, beauty useful means for building the spirit or attitude that is smooth, so the impact on the behavior of people in a quieter handle various problems and will avoid a manner manner driven by excessive emotion, which in turn can lead to loss of control measures, could be detrimental yourself, since it can only be solved by being more beautiful. In practice more attractive to further highlight the aesthetic with an emphasis asana asana variations which are not only classic, preferring a suitable fit with life in modern times.

The point is to develop asana through regular exercise can cure the disease because they work directly on the hormonal system and endocrine glands. Also can increase energy in the body and mind. With asana practical in a relatively slow speed and each pose is repeated several times means aims to balance the secretion of important hormones that can stimulate the function of internal organs and nervous system for peace of mind. Asana is the third part of astangga yoga. In view of yoga Hindu theology has meaning closer to God. and also has a unified sense. Patanjali very clearly introduce the word yoga with silk two yogas ideals vrtti nirodhah, restrict the movements of the mind, control the mind is yoga. In addition yet to find another definition of yoga (yoga magazine dition 12 January 2009: 14). Therefore, universal yoga. Yoga is the purification of the soul of the process of purification of mind and physical body. applying yoga asana in yoga astangga stages continuously means more valuable in the development of physical, mental and spiritual. Yoga is a practical way to achieve unification (Pendit, 2007: 111).

The system of yoga asana practice in the application is not looking at ethnicity, religion and put together in a learning system. Expected by continuous exercise have inner urge for improvement and selfdevelopment. Art physical exercise and if the breath that comes from India to train the mind and can overcome health problems. Yoga from the philosophical point of view it is clear that yoga a concept born out of India evolved in society. The concept of yoga has a philosophy of peace, whoever practice will begin to feel peaceful life and live healthier (BIF Yoga Magazine edition of 12 January 2009: 15). History has recorded that Hinduism is the oldest religion in the world. As Swami Sivananda stated that Hinduism is the mother of all religions, the sacred Hindu texts are the oldest on earth Sivananda (in scolding, 2006: 16). Thus Hinduism is not exclusive to put its teachings, its culture but open, sekurel and not marginalize other ethnic and confidence in achieving life goals.

In veda mentioned Vasudhaiva Kutumbakam. Train yoga means entering a new life full of happy and always eager, which has been tested by yogis in India since thousands of years ago. The practice of meditation in modern life is very important to reduce tension or stress of living in daily activities. By understanding the knowledge of yoga asana, meditation as people will find and be able to sort out which ones are good and which are not good in life. Practices are conducted in yoga is to change all directions in order to get to the inside. Thus there is no remainder for the life to come and be able to obtain the liberation of attachment.

\section{Conclusion}

Based on the analysis of the application of yoga asana learning system in Ananda Marga Ashram can be summarized as follows:

Yoga asanas are developed in Ananda Marga is part of Patanjali Yoga Sutra. Ananda Marga is a community of spiritual study and the practice of yoga asanas. In theology the concept of teaching the same with Hinduism. Organizationally not affiliation, he included Universal movement. Yoga training system adopted in the approach not only classic but more modernized according to the times. With a 
systematic means to build a good human it must build an ethical attitude, aesthetics and able to put culture in the diversity of life so that it can promote harmony, unity, and fraternity to produce peace and happiness. Ananda Marga has a concept of religious experience the same with the same purpose as well, which emphasizes compassion and in Hinduism also emphasizes love. The Hindu philosophy tat tvam asi may cause affection of mutual respect with each other so as to create harmony in life. This means that with mutual respect in diversity then it is really a form of devotion and sense of bhakti forms presented to the Lord.

\section{References}

Anandamurti, Shrii Shrii, 2004. Basic Philosophy of Ananda Marga. Jakarta: IndonesiaAnandaMarga. Anandamitra, Avadhutika, 2012. Beyond Awareness Meditation Supra. Jakarta: Indonesia Ananda Marga.

Bungin, Burhan, 2010. Qualitative Research Data Analysis. Jakarta; King GrafindoPersadaPt.

Clifford, Anne, 2002. Feminist Theology. Yogyakarta: Ledalero

Donder, I Ketut, 2006. Brahmavidya theology of love the universe. Surabaya Paramita.

Ghindawani, Hira, 2006. Universal Hindu religion. Denpasar: Media Hindu.
Kaelan 2005, Qualitative Research Methods Division of Philosophy. Yogyakarta: Paradigm

Koentjaraningrat, 2009. Revised Edition Introduction to Anthropology. Jakarta: PT.Rineka Notices.

Maleong 2010, Qualitative Research Methodology. Bandung: Young Rosdakarya Pt.

Muktananda, Swami, a Hindu spirituality 2007. To Modern Life. Jakarta: Pt Penebar Organization.

Prabhat R S, Shrii, 1992. Yoga Psychology. Jakarta: Ananda Marga

Ritzer, George and Godman, Douglas J., 2011, Modern Sociological Theory. Jakarta: Kencana Predana Media Group.

Saraswati, Swami Satya Prakas. 1996, Patanjali Raja Yoga, Surabaya: Paramita.

Sudarta, 2004. Slokantara. Surabaya: Paramita.Sugiyono, 2010, Educational Research Methods. Bandung: Alfabeta Cv

Smith, mark k, 2009, Theory of Learning and Teaching, Yogyakarta: Mirza Media Library

Titib, I Made, 2001. Theology and symbols in Hinduism. Surabaya: Paramita.

Weber, Max. 2002. Sociology of Religion. Yogyakarta: IRCiSoD 